\title{
Breast augmentation in the transgender patient: narrative review of current techniques and complications
}

\author{
Jenna C. Bekeny ${ }^{1}$, Elizabeth G. Zolper ${ }^{1}$, Oscar J. Manrique ${ }^{2}$, Kenneth L. Fan ${ }^{1,3}$, Gabriel Del Corral ${ }^{1}$ \\ ${ }^{1}$ Department of Plastic and Reconstructive Surgery, MedStar Georgetown University Hospital, Washington, DC, USA; ${ }^{2}$ Department of Plastic and \\ Reconstructive Surgery, Mayo Clinic, Rochester, Minnesota, USA; ${ }^{3}$ MedStar Health Research Institute, Hyattsville, Maryland, USA \\ Contributions: (I) Conception and design: All authors; (II) Administrative support: KL Fan, G Del Corral; (III) Provision of study materials or \\ patients: KL Fan, G Del Corral; (IV) Collection and assembly of data: JC Bekeny, G Del Corral; (V) Data analysis and interpretation: JC Bekeny, G \\ Del Corral; (VI) Manuscript writing: All authors; (VII) Final approval of manuscript: All authors. \\ Correspondence to: Gabriel Del Corral, MD. MedStar Franklin Square Medical Center, 9000 Franklin Square Dr, Baltimore, MD 21237, USA. \\ Email: drgabrieldelcorral@hotmail.com.
}

\begin{abstract}
Gender-affirming surgery (GAS) is often a crucial step during the journey to identity actualization for transgender patients. Surgical breast augmentation, or "top surgery", is frequently cited as the most important and sometimes only gender-affirming procedure sought by transfeminine patients. The breast augmentation process is remarkably similar in transgender and cisgender patients. However, there are unique guidelines, anatomic considerations, and contextual issues for the transgender patient population that must be taken into account by providers to achieve optimal outcomes. The aim of this review is to outline the current state of breast augmentation for transfeminine patients. We walk through our suggested pre-surgical evaluation, breast augmentation options, and post-surgical care. In the preoperative period, providers must establish a positive provider-patient relationship that allows for thorough history taking, physical examination, and goal setting. Providers must be able to select an appropriate implant, incision location, and operative plane to balance patient desires and pre-existing anatomic characteristics in transfeminine patients. Postoperatively, the provider must address acute and chronic needs to allow for continued satisfaction and safety. After reading this review, we aim for providers to be well-equipped to provide the highest quality breast augmentation care for their transfeminine patients. As research into best practices for breast augmentation in transfeminine patients continues to develop, we expect that surgical practice will continue to evolve.
\end{abstract}

Keywords: Transgender; gender dysphoria; breast augmentation; mammaplasty; gender confirmation procedures

Submitted Jul 02, 2020. Accepted for publication Jan 29, 2021.

doi: $10.21037 / \mathrm{atm}-20-5087$

View this article at: http://dx.doi.org/10.21037/atm-20-5087

\section{Introduction}

Any discussion of gender-affirming surgery (GAS) for transgender patients should begin with an examination of the field's history. Regrettably, care for transgender patients has been obstructed on the individual and systemic levels. While gender affirming procedures have longexisted, awareness of transgender-specific surgical needs was propelled by Dr. Harry Benjamin and his care for
Christine Jorgenson, an American actress and army veteran who publicly sought feminizing transition (1). Through his efforts, Dr. Benjamin laid the groundwork for GAS in the public sphere (1).

In the United States of America, as many as $0.6 \%$ of adults or 1.4 million people, currently identify as transgender; worldwide estimates of the transgender population range from $0.4 \%$ to $1.3 \%$ (2). Estimates show a slightly higher representation of transfeminine individuals $(1: 11,900$ to 
$1: 45,0000)$ when compared to transmasculine individuals $(1: 30,400$ to $1: 200,000)(3)$. Regional variation exists as well with some locations, such as the District of Columbia, reporting percentages of transgender individuals as high as $2.8 \%$ (2). Of note, formal epidemiologic studies on the true population of transgender individuals are challenging. Estimates often come from single institution data, which are then extrapolated to state-wide or nation-wide scales (3). These numbers only capture data on patients who both have access to transgender-specific healthcare and experience gender dysphoria to a degree in which transgender-specific healthcare is required (3-5). Gender dysphoria can be defined as the discrepancy between assigned sex at birth and gender identity that leads to discomfort or distress (3). The true population of transgender individuals is likely higher than reported.

In 1981, GAS was excluded as a covered expense by the United States Department of Medicare (1). It was not until 2014, that this ruling was overturned as research demonstrated the safety, efficacy, and non-experimental nature of GAS $(1,6)$. Insurance coverage of GAS has been a well-documented barrier to healthcare access that is finally beginning to shift $(7,8)$. Lane et al. analyzed Truven MarketScan data from 2009 and 2015 for all encounters coded for gender identity disorder, and their analysis discovered year-by-year increases in GAS utilization (9). Canner et al. performed a large-scale analysis of all inpatient healthcare encounters for transgender patients using 14 years of data from the National Inpatient Sample (NIS) (10). Their group discovered a three-fold increase in Medicare and Medicaid coverage for transgender patients in 2014 with incidence of GAS rising in parallel to the increased insurance coverage (10).

Unfortunately, healthcare coverage remains tumultuous as inclusions under Section 1557 of the Affordable Care Act continue to be debated. On June 12, 2020, the Department of Health and Human Services redefined discrimination of sex as strictly biological sex instead of the Obama-era definition including sexual orientation and gender identity, opening an avenue for insurance companies to decline payment and reimbursement (11). Three days later the Supreme Court ruled in a historic 6-3 decision that sex included gender identity and sexual orientation in a case regarding Title VII of the Civil Rights Act, setting the stage for lawsuits to challenge the Department of Health and Human Services' reversal of transgender protection. While more work is necessary to topple pervasive exclusion from healthcare, our field is on track to increasingly provide for transgender patients.

We aim for this review to increase provider understanding of transfeminine breast augmentation. This review will take readers through (I) preoperative evaluation and guideline adherence (II) operative considerations unique to transfeminine patients and (III) early and late postoperative care. We present the following article in accordance with the Narrative Review reporting checklist (available at http://dx.doi.org/10.21037/atm-20-5087).

\section{Methods}

\section{Literature review}

We conducted a literature search for papers published up to the year 2020 on the approach to breast augmentation in transfeminine patients. Databases used in this search included PubMed and Ovid MEDLINE. Various MeSH terms, such as "Transgender", "Transgender Persons", "Gender Dysphoria", "Gender Confirmation Surgery", "Gender Confirmation Procedures", and "Mammaplasty", and keywords, such as "Transfeminine", "Breast Augmentation", and "Top Surgery", were used to identify articles for inclusion in this review. Articles were limited to those published in the English language.

An initial pull of 5,803 articles was identified using these parameters. After screening article titles and abstracts, 59 papers and their reference lists were included for fulltext review. While an exhaustive systematic review was not performed, standard systematic review methodology was used to ensure high-quality information was obtained for this review.

\section{Surgical experience data}

Transfeminine patients undergoing implant-based breast surgery between 2018 and 2020 were retrospectively reviewed. Patient demographics, such as age and race, and comorbid conditions, such as BMI, smoking history, and Charlson comorbidity index (CCI), were collected (12). Details on the surgical procedure, such as implant size, incisional location, and implant plane, were collected. A total of 37 patients were included.

\section{Preoperative guidelines, evaluation, and considerations}

Since 1979, the World Professional Association for 
Transgender Health (WPATH) has outlined Standards of Care (SOC) as clinical guidance for providers offering surgical and nonsurgical gender-affirming care. The SOC draws on current research to provide both mandatory and suggested components of the preoperative workup for transfeminine patients seeking top surgery. Before surgery, all patients must be at an accepted age for consent, and all patients must have the capacity to give informed consent (3). All transgender patients must have well-documented, persistent gender dysphoria before surgical intervention is undertaken (3). The SOC mandates that all transfeminine patients seeking breast augmentation receive one referral from a qualified mental health professional. Significant medical or mental health concerns must be appropriately managed preoperatively (3). While not mandatory, the SOC suggest that all transfeminine patients take exogenous hormones for a minimum of twelve months (3). This suggestion is to maximize an increase in parenchymal breast tissue, leading to a better cosmetic outcome after breast augmentation. In order to fulfill requirements and suggestions outlined in the SOC, a multidisciplinary team should be involved early in the preoperative period. Endocrinologists or primary care doctors experienced with transgender care can manage exogenous hormone use. Psychiatrists specializing in transgender health are needed for referrals and are instrumental in ensuring all psychiatric concerns are well-managed.

The preoperative period is especially important when offering surgical care to transgender patients. From the first patient visit, all providers must establish a respectful and equitable relationship. Unfortunately transgender patients face higher rates of suicidality, physical assault, sexual abuse, and lethal violence when compared to cisgender peers (13). Specific to healthcare, transgender patients report alarmingly high rates of unsupportive, illinformed, and hostile physicians (13). Providers can work to overcome this history by affirming the patient's gender identity and inquiring about the patient's preferred name and pronouns (14). Patient preferences may not align with a particular gender or identity category, so providers must document what the patient prefers. Patients may refer to breast augmentation as "top surgery," so it is important to acknowledge and document a patient's preferred way of speaking about their procedure.

For transfeminine breast augmentation, providers must take a detailed patient history that focuses on any steps the patient has taken in the chest feminizing process. As previously mentioned, exogenous hormones should be taken for at least a year to prepare for surgical augmentation by maximizing growth of native tissues (15).
Some groups advocate for stopping exogenous hormone use approximately two to four weeks prior to surgery (16). The thought is that exogenous estrogen increases the risk of thromboembolic events. However, this practice is controversial due to low incidence of thromboembolic events coupled with the deleterious effects of stopping hormone use in the transgender population (16). In our practice, we no longer stop exogenous hormone use, and we have not documented any changes in thromboembolic event frequency.

Unfortunately, some transfeminine patients seek "street" hormones and illicit silicone injections as an alternative to physician-prescribed gender affirming medications and procedures. These substances have been issued warnings by the U.S. Food and Drug Administration, but the lowcost and the ability to obtain these substances outside of the medical setting make them unfortunately attractive options for patients who distrust or cannot access the medical community $(17,18)$. If a history of self-obtained substances is disclosed, providers should take this into account when formulating a surgical plan (19). In our practice we see a significant number of patients, who use both street hormones and illicit silicone injections. The 2015 U.S. Transgender Survey (USTS) discovered that approximately $8 \%$ of those surveyed used street hormones and 3\% used illicit silicone injections (20). These numbers are estimated to be as high as $29-63 \%$ in urban transgender patient populations (21). Analysis of our transgender patients undergoing breast augmentation reveals that $21.5 \%$ of patients used street hormones, illicit silicone injections, or both in an attempt to meet their gender actualization needs. Despite these high rates of use, complication rates were incredibly low with no patients requiring revision. Breast augmentation can, in our opinion, be safely performed in patients with a history of illicit augmentation substance use as long as appropriate evaluation and expectation management is performed. Patient demographics and comorbid conditions are outlined in Table 1.

For all patients, systemic illnesses and medications must be assessed preoperatively to ensure risk of complications is reduced. Breast surgery impairs tissue vascularity, so any agents that cause vasoconstriction, such as nicotine, cocaine, and methamphetamines, must be stopped preoperatively (16). $40.5 \%$ of our transfeminine patients have some degree of tobacco history, highlighting the prevalence of tobacco use and the importance of screening for its use. Wound healing capabilities are maximized with smoking cessation as well (15). In patients with diabetes, HbA1c should be below $7.0 \%$ to 
Table 1 Demographic, comorbid conditions, and surgical technique for 37 transfeminine patients undergoing breast augmentation between the years 2018 and 2020

\begin{tabular}{lc}
\hline Characteristic & Mean (SD) or N (\%) \\
\hline Demographic and comorbid conditions & $32.7(9.2)$ \\
Age at surgery (years) & \\
Race & $23(62.2 \%)$ \\
African American & $5(13.5 \%)$ \\
White & $9(24.3 \%)$ \\
Other & $26.7(5.9)$ \\
BMI (kg/m $\left.{ }^{2}\right)$ & $0.3(0.8)$ \\
Charlson comorbidity index & \\
Smoking history & $22(59.5 \%)$ \\
None & $5(13.5 \%)$ \\
Prior & $10(27.0 \%)$ \\
Current & $34(91.9 \%)$ \\
History of illicit silicone injections or hormone use & $29(78.4 \%)$ \\
No & $8(21.6 \%)$ \\
Yes & \\
Surgical characteristics & \\
Incision location & \\
Subramammary fold & \\
\hline
\end{tabular}

minimize cardiovascular and infectious complications (16).

\section{Surgical techniques}

The most common method for transfeminine patients to achieve their desired chest appearance involves the surgical placement of implants. Surgical breast augmentation is very similar in transgender and cisgender patients, overall. Transgender-specific recommendations for implant sizing and selection, incision placement, and operative plane are developing (22). Providers must account for certain differences in their transgender patients in order to provide the optimal surgical and aesthetic outcomes. Figure 1 outlines considerations that should be made in the breast augmentation process.

The genetic male and genetic female anatomy differ in a few aspects that are necessary to evaluate and account for during transfeminine breast augmentation. A genetically male individual has years of exposure to androgenic hormones that develop relatively broad shoulders, wide sternum, shortened nipple to inframammary fold distance, hypertrophied pectoralis majors, and small, ovoid, lateralized nipple areolar complexes (NAC) $(23,24)$. Transfeminine patients who take exogenous hormones commonly develop asymmetric breast tissue growth. Certain operative techniques can accommodate these differences and yield highly satisfactory surgical outcomes.

In the transfeminine patient, sizers are helpful to determine the best implant size to achieve a symmetric result. $16.2 \%$ of our transfeminine patients require implants of different size to achieve symmetry, with difference in volumes averaging $46.7 \mathrm{cc}$ (SD 18.3). Genetic males often have a small, lateralized NAC. Achieving a feminized NAC requires both size increase and centralization of this structure. Size is often somewhat increased with the placement of implants, since they stretch the overlying skin (24). Implants should be placed directly behind the nipple, and implants with wider base width can help to balance nipple position and cleavage formation. In extreme lateralization, centralization of the NAC can be achieved via periareolar mastopexy. This procedure can be performed simultaneously with breast augmentation in experienced providers. Patients must be counseled of the risk carried by this additional procedure and incision location-nipple sensitivity changes, NAC necrosis, etc. Similarly, breast implant lateralization due to hypertrophied pectoralis major can be compensated for with elevation of medial pectoralis major fibers. However, over-elevation will lead to challenging medial migration of implants and symmastia.

Preoperatively, patient and provider must agree on implant sizing, implant selection, incision location, and operative plane. Of note, several studies demonstrate that provider and patient ideals for breast augmentation differ widely, with patients often desiring larger breasts with defined cleavage (24). In a 20 -year follow-up study of transfeminine patients who had undergone breast augmentation, the most common reason for secondary procedures was to increase implant size (25). At revision, implant size increased significantly, with an average size increase of $107.0 \mathrm{cc}$ (SD $48.1 \mathrm{cc}$ ) compared to the primary implants (25). Average initial implant size increased over the study period as well, indicating increased desire for 


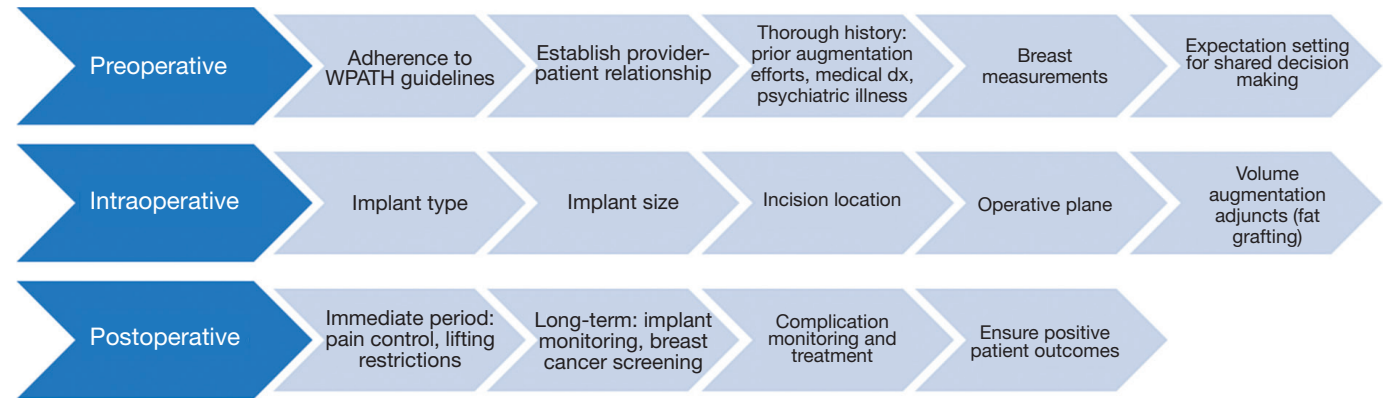

Figure 1 Proposed preoperative, intraoperative, and postoperative considerations for providing quality care to transfeminine patients seeking breast augmentation. This schematic should evolve as research uncovers best practices specific to transgender patient care.

larger breasts (25). It is imperative that providers counsel patients preoperatively about the limitations on size due to the native breast skin envelope and nascent breast tissue. Other authors report that more than half of their patients would select larger implant sizes if not for anatomic and operative restrictions (26). On average, implant size for our transfeminine patients is $448.1 \mathrm{cc}$ (SD $121.4 \mathrm{cc}$ ) (Figure 2A,B).

Breast augmentation incision location for transfeminine patients can include any of the standard techniques used for cisgender patients—axillary, inframammary, or periareolar (27). In inframammary incisions, the new inframammary fold (IMF) should be placed lower than the native line to accommodate the future downward implant settling (27). This is especially important in transfeminine patients since failure to lower the IMF results in excessive upper pole fullness and a downward facing NAC (26). Mallucci and Branford proposed a simple, prospectively validated method for calculating the ideal location of the IMF incision. The "ICE" method takes the implant dimensions (I), breast capacity $(\mathrm{C})$, and excess tissue $(\mathrm{E})$ into account in the equation, $\mathrm{I}-\mathrm{C}=\mathrm{E}$ (28). I represents half of the implant height plus the projection; $\mathrm{C}$ is the nipple-to-IMF distance when the breast tissue is stretched; $\mathrm{E}$ is the distance by which the IMF must be lowered (28). The Ranquist formula is another useful system for appropriate lowering of the IMF. This formula uses the base width of the implant to suggest the new nipple to IMF distance (Table 2). For our transfeminine patients, we routinely use the Ranquist formula, and find that on average the IMF should be lowered at least $3 \mathrm{~cm}$.

The implant plane for transfeminine breast augmentation is commonly in the prepectoral or subpectoral plane (25). Both methods have been used with success, but certain patient characteristics should sway provider decision on which plane to use. Tebbetts and Adams proposed a comprehensive algorithm for choosing the appropriate implant and procedural characteristics known as the High
Five or TEPID system (29). Their group suggests dualplane or partial subpectoral implant placement in patients with a "pinch test" less than $2.0 \mathrm{~cm}$ (29). A pinch test is performed by gently grasping native breast tissue superior to the NAC between the thumb and index finger. Implant plane placement based on pinch test results helps to reduce concerns with postoperative malposition or animation deformity. The pinch test has recently been adapted into a transfeminine-specific algorithm for plane selection (26). This updated algorithm suggests using the prepectoral plane in patients with a "pinch test" $>1.5 \mathrm{~cm}$ and skin softening coupled with signs of androgen exposure Mallucciexcess sternal bone width and pectoral hypertrophy (26). Of note, their group recommends that patients who have a history of silicone injections should receive dual-plane subpectoral placement regardless of tissue characteristics (26). In our practice, we routinely use the prepectoral plane for patients with Tanner stage IV or $\mathrm{V}$ breast development, due to lower postoperative pain levels (27). Prepectoral implant placement may lead to higher rates of capsular contracture and a more lateralized breast (30). The majority of our transfeminine patients $(\mathrm{n}=34,91.9 \%)$ undergo prepectoral implant placement. Few of our patients $(n=3,8.1 \%)$ require dual plane implant placement. Since revisions are more challenging to perform and it is difficult to obtain insurance coverage, we recommend thorough preoperative discussion of these risks and benefits. Of note, we do not routinely use drains in our breast augmentation practice (Figures $3 A, B, C, D, 4 A, B, C)$.

Fat grafting is a useful adjunct to breast-implant placement to achieve desired volume. Fat grafting is rarely used as the sole method of transfeminine breast augmentation. However, this procedure is especially useful for reducing implant visibility and palpability and it offers a more natural appearing counter $(16,27)$. Take rates for 

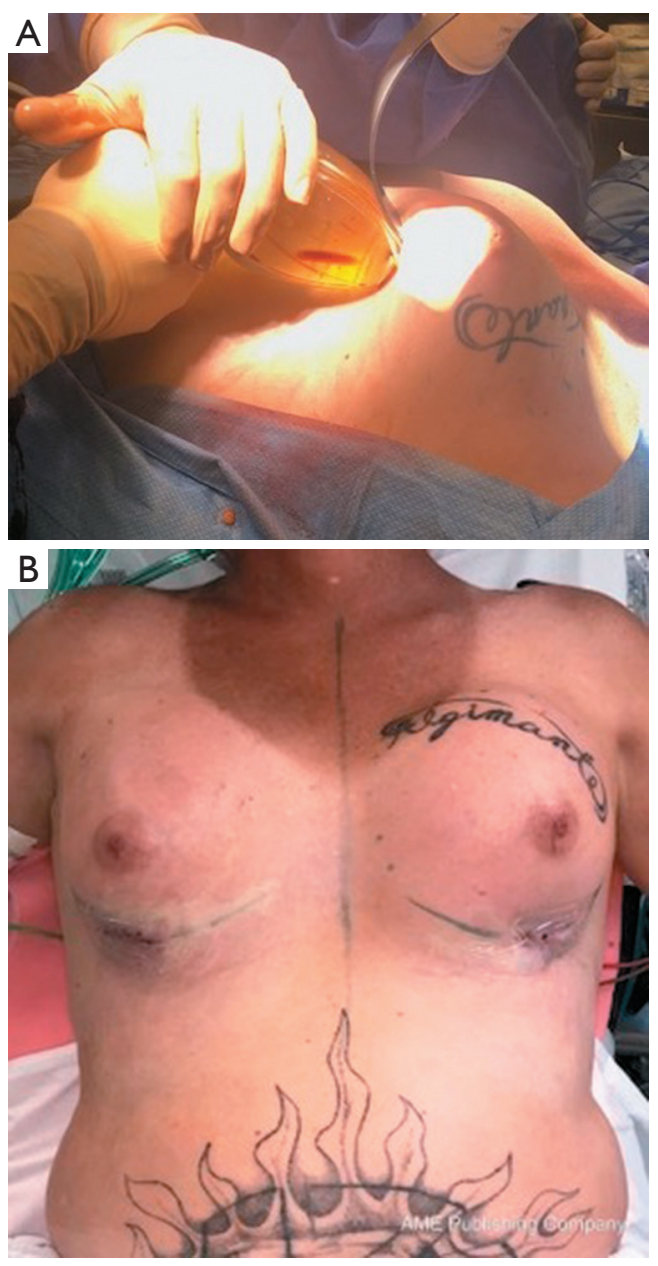

Figure 2 These images depict the intraoperative technique and immediate postoperative results of implant placement in a transfeminine patient. (A) Insertion of implant for transfeminine breast augmentation via an inframammary fold incision. The pre-existing breast tissue comes from several years of exogenous hormone use. (B) Implant plane selection should be made carefully. In our practice, we routinely use the prepectoral plane for patients with Tanner stage IV or V breast development, due to lower postoperative pain levels.

fat grafting range from $50-60 \%$, so multiple procedures are often needed to achieve the desired outcome $(15,27)$. Unfortunately, fat grafting is not routinely covered by insurance, and patients must pay out of pocket for this procedure. Having to pay out of pocket limits frequency of this procedure.

Of note, use of textured implants cannot be recommended for transfeminine patients due to the risk of anaplastic large cell lymphoma (ALCL). Case reports indicate that textured implant
Table 2 The Ranquist formula provides an estimation for inframammary fold lowering. This table aims to help providers select an appropriate disease for lowering to achieve the most natural appearing post-operative result

\begin{tabular}{lc}
\hline Implant width $(\mathrm{cm})$ & $\begin{array}{c}\text { New Nipple to inframammary fold } \\
\text { distance }(\mathrm{cm})\end{array}$ \\
\hline 11.0 & $7.5 \pm 0.5$ \\
11.5 & $8.0 \pm 0.5$ \\
12.0 & $8.5 \pm 0.5$ \\
12.5 & $9.0 \pm 0.5$ \\
13.0 & $9.5 \pm 0.5$ \\
\hline
\end{tabular}

placement in transfeminine patients is linked to ALCL.

\section{Postoperative care}

The immediate postoperative care of transfeminine patients undergoing breast augmentation is similar to the care for cisgender patients. All postanesthesia care unit workers should be trained to care for transgender patients (31). Transgender patients face disproportionate amount of prejudice and hostility within the medical setting. Their immediate postoperative setting places them at increased vulnerability. All stuff must be trained on respectful terminology and pronoun use. Short-term care involves implant massage to soften the overlying breast skin and proper brasserie fitting (16). We recommend that patients avoid heavy lifting for at least four to six weeks (15).

Long-term postoperative care involves implant imaging and breast cancer screening. Breast implants are not classified by the FDA as lifetime devices. For silicone implants, patients should undergo magnetic resonance imaging (MRI) three years after implantation and every two years after that (15). Transfeminine patients who have taken exogenous hormones for at least five years and are 50 years or older should begin breast cancer screening. Although rare, all patients should be counseled on breast implantassociated anaplastic large cell lymphoma (BIA-ALCL), which is related to textured implant placement (32-34). Presenting symptoms include late-onset fluid collection, overlying skin discoloration, and pruritis (33). We do not recommend use of textured implants for transfeminine breast augmentation. Patients who underwent a previous augmentation with a textured implant should be informed of the risk of BIA-ALCL, its symptoms, and avenues for implant exchange. 

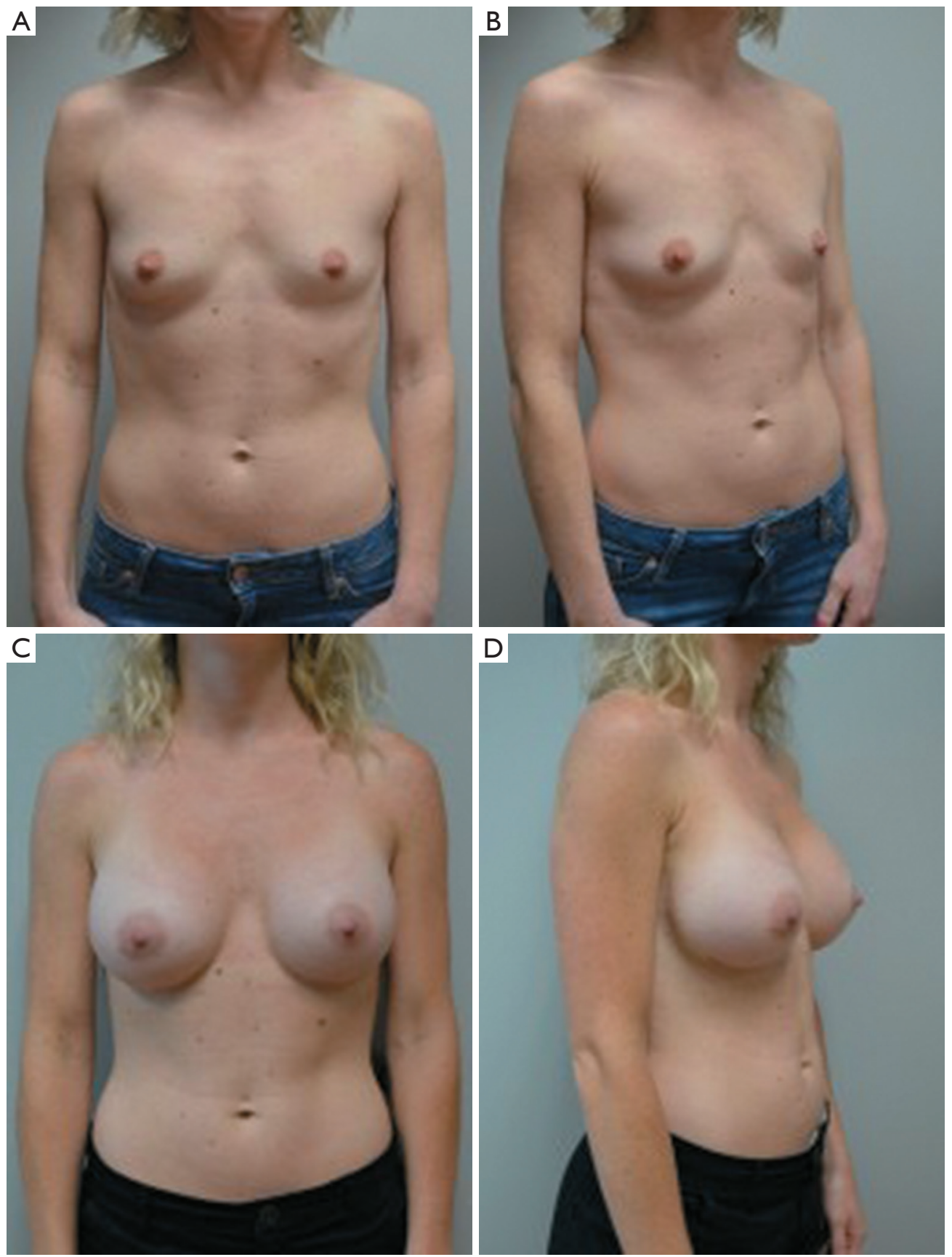

Figure 3 These images demonstrate the preoperative anatomy and postoperative results of a patient undergoing breast implantation with dual plane position. (A) This image shows a patient before breast implant surgery. This patient achieved some degree of breast growth with years of exogenous hormone use. (B) The pinch test is a useful method to determine the appropriate plane selection for implant placement. In this patient, a pinch test less than $2 \mathrm{~cm}$ was achieved, so the prepectoral plane could not be used for implant placement. (C) By using the dual plane location, this patient was able to achieve desired breast size and cleavage. Centralization of the nipple areolar complex helps to produce a more natural breast appearance. (D) While few of our patients require dual plane placement for breast implants, highly aesthetic results can be achieved. 

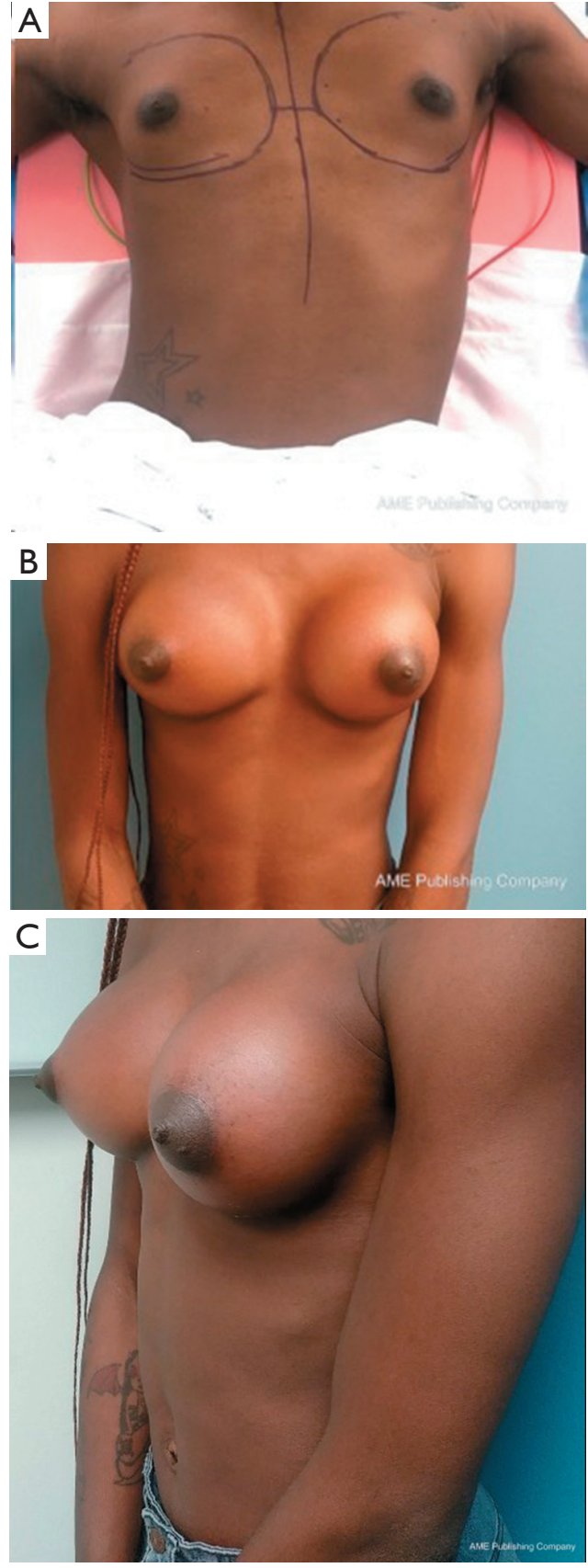

Figure 4 These images show the preoperative anatomy and postoperative results of a patient undergoing breast implantation in the prepectoral plane position. (A) This image depicts the patient before surgery. The reader can visualize some degree of breast growth secondary to exogenous hormone use. (B) Postoperatively, the patient achieved desired breast size and cleavage with prepectoral implant placement. Using the prepectoral plane for breast implant placement is typically associated with lower postoperative pain scores. (C) With time, breast implants settle into a more natural position and yield suitable aesthetic outcomes for patients.

\section{Complications}

Complication rates in breast augmentation are low, regardless of whether the procedure is performed in cisgender or transfeminine patients. Recently, Cuccolo et al. reviewed 10 years of data from the National Surgical Quality Improvement Program (NSQIP) database. On dividing breast augmentation patients into cisgender and transfeminine cohorts, they identified low $(1.8 \%$ versus $1.6 \%$, respectively) and non-statistically different rates of 30-day complications $(\mathrm{P}=0.890)$ (35). Lane et al. investigated complication incidence over the full spectrum of GAS using data from TruvenMarket scan (9). In this catch-all analysis, total complications occurred in only $5.8 \%$ of operations. Of note, complications were lowest in breast-based procedures and highest in genitalbased procedures. However, complications affect certain subpopulations disparately. Using data from NSQIP and the National Inpatient Sample (NIS), Tran et al. identified that being of black or African American race increased risk of reoperation and readmission independent of all other factors (36).

Long-term complications of breast implantation in transfeminine patients are the same as those in cisgender patients—symmastia, capsular contracture, reduced breast or nipple sensation, implant leakage, or implant migration. Anecdotally, revisional procedures in transfeminine patients are challenging due to already thin breast tissue and skin coverage. However, secondary procedures can be undertaken and produce acceptable results. Of note, revisional procedures are often not covered by insurance. We suggest thorough preoperative discussion with patients about this. Overall, implant-based breast augmentation remains a safe procedure. Patient regret after breast augmentation, while rare, occasionally occurs. A study noted that $0.6 \%$ of transfeminine and $0.3 \%$ transmasculine patients who underwent genital-based gender affirming surgery felt some degree of regret after 30-years of follow-up (37). Data on breast or chest-based procedures remains lacking. Supposed reasons for postprocedural regret include poor operative outcomes, surgical complications, and lack of social support from family and partners (38).

\section{Conclusions}

Breast augmentation is often a critical step in a transfeminine patient's surgical experience. With thorough understanding of the unique personal and anatomic needs 
of transfeminine patients, providers will make appropriate breast augmentation decisions. This understanding allows providers to perform this procedure safely with highly acceptable aesthetic and patient satisfaction results. Complication rates are low and are comparable to those seen in cisgender patients undergoing analogous procedures. As the social and political climate continues to evolve, we anticipate increased numbers of transfeminine patients seeking breast augmentation.

\section{Acknowledgments}

Funding: None.

\section{Footnote}

Provenance and Peer Review: This article was commissioned by the editorial office, Annals of Translational Medicine, for the series "Transgender Surgery". The article has undergone external peer review.

Reporting Checklist: The authors have completed the Narrative Review reporting checklist. Available at http:// dx.doi.org/10.21037/atm-20-5087

Peer Review File: Available at http://dx.doi.org/10.21037/ atm-20-5087

Conflicts of Interest: All authors have completed the ICMJE uniform disclosure form (available at http://dx.doi. org/10.21037/atm-20-5087). The series "Transgender Surgery" was commissioned by the editorial office without any funding or sponsorship. OJM served as the unpaid Guest Editor of the series. The authors have no other conflicts of interest to declare.

Ethical Statement: The authors are accountable for all aspects of the work in ensuring that questions related to the accuracy or integrity of any part of the work are appropriately investigated and resolved.

Open Access Statement: This is an Open Access article distributed in accordance with the Creative Commons Attribution-NonCommercial-NoDerivs 4.0 International License (CC BY-NC-ND 4.0), which permits the noncommercial replication and distribution of the article with the strict proviso that no changes or edits are made and the original work is properly cited (including links to both the formal publication through the relevant DOI and the license). See: https://creativecommons.org/ licenses/by-nc-nd/4.0/.

\section{References}

1. Berli JU, Knudson G, Fraser L, et al. What Surgeons Need to Know About Gender Confirmation Surgery When Providing Care for Transgender Individuals: A Review. JAMA Surg 2017;152:394-400.

2. Flores AR, Herman JL, Gates GJ, et al. How Many Adults Identify As Transgender in the United States? Williams Inst 2016;(June):13.

3. Coleman E, Bockting W, Botzer M, et al. Standards of Care for the Health of Transsexual, Transgender, and Gender-Nonconforming People [Internet]. International Journal of Transgenderism. [cited 2019 Nov 20]. Available online: www.wpath.org

4. El-Hadi H, Stone J, Temple-Oberle C, Harrop AR. Gender-affirming surgery for transgender individuals: Perceived satisfaction and barriers to care. Plast Surg (Oakv) 2018;26:263-8.

5. Roberts TK, Fantz CR. Barriers to quality health care for the transgender population. Clin Biochem 2014;47:983-7.

6. Division A, Appeals Board D, of Health D, Services H. Department of Health and Human Services DEPARTMENTAL APPEALS BOARD Appellate Division 2014 [cited 2019 Nov 25]. Available online: http://www.socialsecurity.gov/OP_Home/ssact/ssacttoc.htm

7. Ngaage LM, Knighton BJ, McGlone KL, et al. Health Insurance Coverage of Gender-Affirming Top Surgery in the United States. Plast Reconstr Surg 2019;144:824-33.

8. Learmonth C, Viloria R, Lambert C, et al. Barriers to insurance coverage for transgender patients. Am J Obstet Gynecol 2018;219:272.e1-272.e4.

9. Lane M, Ives GC, Sluiter EC, et al. Trends in genderaffirming surgery in insured patients in the United States. Plast Reconstr Surg Glob Open 2018;6:e1738.

10. Canner JK, Harfouch O, Kodadek LM, et al. Temporal trends in gender-affirming surgery among transgender patients in the United States. JAMA Surg 2018;153:609-16.

11. Section 1557 of the Patient Protection and Affordable Care Act I HHS.gov [Internet]. [cited 2020 Jun 23]. Available online: https://www.hhs.gov/civil-rights/for- 
individuals/section-1557/index.html

12. Charlson ME, Pompei P, Ales KL, et al. A new method of classifying prognostic comorbidity in longitudinal studies: Development and validation. J Chronic Dis 1987;40:373-83.

13. Winter S, Diamond M, Green J, et al. Transgender people: health at the margins of society. Lancet 2016;388:390-400.

14. Wesp LM, Deutsch MB. Hormonal and Surgical Treatment Options for Transgender Women and Transfeminine Spectrum Persons. Psychiatr Clin North Am 2017;40:99-111.

15. Van Boerum MS, Salibian AA, Bluebond-Langner R, et al. Chest and facial surgery for the transgender patient. Transl Androl Urol 2019;8:219-27.

16. Narayan SK, Morrison T, Dugi DD, et al. Gender Confirmation Surgery for the Endocrinologist. Endocrinol Metab Clin North Am 2019;48:403-20.

17. Prasetyono TOH, Sadikin PM. Management of asymptomatic silicone-injected breast with reduction mammoplasty. Indian J Plast Surg 2015;48:317-20.

18. FDA Warns Against Use of Injectable Silicone for Body Contouring and Enhancement: FDA Safety Communication I FDA [Internet]. [cited 2020 Jun 23]. Available online: https://www.fda.gov/medical-devices/ safety-communications/fda-warns-against-use-injectablesilicone-body-contouring-and-enhancement-fda-safetycommunication

19. Leonardi NR, Compoginis JM, Luce EA. Illicit Cosmetic Silicone Injection: A Recent Reiteration of History. Ann Plast Surg 2016;77:485-90.

20. James SE, Herman JL, Rankin S, et al. The report of the 2015 U.S. Transgender Survey. Natl Cent Healthc Equal 2016;302. Available online: http://www. transequality.org/sites/default/files/docs/USTS-FullReport-FINAL.PDF

21. Sanchez NF, Sanchez JP, Danoff A. Health care utilization, barriers to care, and hormone usage among male-tofemale transgender persons in New York City. Am J Public Health 2009;99:713-9.

22. Miller TJ, Wilson SC, Massie JP, et al. Breast augmentation in male-to-female transgender patients: Technical considerations and outcomes. JPRAS Open 2019;21:63-74.

23. Safa B, Lin WC, Salim AM, et al. Current Concepts in Feminizing Gender Surgery. Plast Reconstr Surg 2019;143:1081e-1091e.

24. Morrison SD, Wilson SC, Mosser SW. Breast and Body Contouring for Transgender and Gender Nonconforming
Individuals. Clin Plast Surg 2018;45:333-42.

25. Fakin RM, Zimmermann S, Kaye K, et al. Long-Term Outcomes in Breast Augmentation in Trans-Women: A 20-Year Experience. Aesthet Surg J 2019;39:381-90.

26. Coon D, Lee E, Fischer B, et al. Breast Augmentation in the Transfemale Patient: Comprehensive Principles for Planning and Obtaining Ideal Results. Plast Reconstr Surg 2020;145:1343-53.

27. Claes KEY, D'Arpa S, Monstrey SJ. Chest Surgery for Transgender and Gender Nonconforming Individuals. Clin Plast Surg 2018;45:369-80.

28. Mallucci P, Branford OA. Design for Natural Breast Augmentation: The ICE Principle. In: Plastic and Reconstructive Surgery. Lippincott Williams and Wilkins, 2016:1728-37.

29. Tebbetts JB, Adams WP. Five critical decisions in breast augmentation using five measurements in 5 minutes: the high five decision support process. Plast Reconstr Surg 2005;116:2005-16.

30. Kanhai RCJ, Hage JJ, Asscheman H, et al. Augmentation mammaplasty in male-to-female transsexuals. Plast Reconstr Surg 1999;104:542-9.

31. Tollinche LE, Burrows Walters C, Radix A, et al. The perioperative care of the transgender patient. Anesth Analg 2018;127:359-66.

32. de Boer M, Van Der Sluis WB, De Boer JP, et al. Breast implant-associated anaplastic large-cell lymphoma in a transgender woman. Aesthet Surg J 2017;37:NP83-7.

33. Ali N, Sindhu K, Bakst RL. A Rare Case of a Transgender Female With Breast Implant-Associated Anaplastic Large Cell Lymphoma Treated With Radiotherapy and a Review of the Literature. J Investig Med High Impact Case Rep 2019;7:2324709619842192.

34. Patzelt M, Zarubova L, Klener P, et al. Anaplastic LargeCell Lymphoma Associated with Breast Implants: A Case Report of a Transgender Female. Aesthetic Plast Surg 2018;42:451-5.

35. Cuccolo NG, Kang CO, Boskey ER, et al. Epidemiologic Characteristics and Postoperative Complications following Augmentation Mammaplasty. Plast Reconstr Surg Glob Open 2019;7:e2461.

36. Tran BNN, Epstein S, Singhal D, et al. A Synopsis Using American College of Surgeons National Surgery Quality Improvement Program and National Inpatient Sample Databases. Ann Plast Surg 2018;80:S229.

37. Wiepjes CM, Nota NM, de Blok CJM, et al. The Amsterdam Cohort of Gender Dysphoria Study (1972- 
2015): Trends in Prevalence, Treatment, and Regrets. J Sex Med 2018;15:582-90.

38. Djordjevic ML, Bizic MR, Duisin D, et al. Reversal

Cite this article as: Bekeny JC, Zolper EG, Manrique OJ, Fan KL, Del Corral G. Breast augmentation in the transgender patient: narrative review of current techniques and complications. Ann Transl Med 2021;9(7):611. doi: 10.21037/ atm-20-5087 surgery in regretful male-to-female transsexuals after sex reassignment surgery. J Sex Med 2016;13:1000-7. 